\title{
PLANNING IN CONTEMPORARY MANAGEMENT CONDITIONS
}

\author{
Slobodan N. Bracanović
}

DOI: https://doi.org/10.31410/LIMEN.2019.15

\begin{abstract}
Planning has increasingly been gaining in significance in a more recent period and at all levels. There is also room for developing more perfect and newer forms of planning. The market is becoming an economic space both as the subject matter of contemporary business planning and the subject matter of a contemporary plan. The management structure (i.e. management) is not only faced with dilemmas regarded as either plan or market dilemmas, but rather as both plan and market dilemmas.
\end{abstract}

Keywords: Planning, Plan, Visionary ability, Horizon, Strategy, Tactics, Operation plan, Operationality.

\section{PRIOR DETERMINANTS}

Dlanning from the highest macro-aspect (as well as the central level, i.e. the mezzo-aspect) implies a form of the conscious, rational coordination and directing of economic, branch, regional and social-economic development, which is gaining in significance with the new role of the state.

The micro-aspect of management implies planning as denoting the primary function of the management process. Namely, planning is the first (initial) of the equal functions (phases, stages, subsystems, segments) of the management process. In the same manner, planning basically starts, generates (initiates) and intensifies the activities of organizing (labor, manufacturing, services), decision-making, leading and handling, and control activities. The absence of planning leads to chaos.

The causes for, origins of and reasons for the necessity of planning are complex and intricate: 1 . the organization and direction of the activities to be performed by managers and (or) employees in organizations (i.e. a vision, a mission, ideas, goals, motives, a strategy, tactical and operational short- and long-term plans) are oriented; 2. a lack of organization, a lack of occupation, a lack of order and a chaotic atmosphere are reduced; 3. redundant, irrational, non-purposeful and ancillary (supplementary) activities are reduced; 4. planning decisions promulgated are determined as the benchmark (i.e. "standard") of control; 5. the future (in an internal, external and connected environment) is predicted, and we always aspire to direct, adapt and control the future and reduce entropy (the immanent tendency of a system to move towards uncertainty, chaos and destruction); 6. omissions, misses and mistakes that have been made are corrected and rectified; 7. the possibilities of making changes in working are perceived, etc. Apart from this, approaches to planning may be diverse. Planning is a) the basis for the decision-making process (making individual, concrete decisions), also including (encompassing) the related integral process (system) of determining decisions themselves; b) the application of formalized techniques, rules, procedures and methods; c) minimizing economic, business riskiness; d) perceiving entrepreneurship flows; e) thinking, creative working out and "control" of the future, and so on. A whole "panoply" of approaches are also possible to apply. 
Planning is also possible to interpret (in a narrower sense) as the flow (process) of determining and making planning decisions. Different planning decisions are immanent: intercausal, interdependent, inter-conditioned and integrated (in an integral system). Planning decisions arise from a vision, mission and ideas (leading ideas and ideals) of business entities and, more broadly perceived, organizations, further including goals, means, projections, concepts, strategies and plans. It is possible to generate planning decisions in a formalized process based on relevant planning methodologies, and frequently on the unformalized development of processes, whereas interwoven ("cross" and other) flows are also beyond dispute. Information (data, facts) are the underpinning for making timely and quality planning decisions. This has been made possible by the modern, fast, expansive development of the cybernetic and computer systems. The informational basis was much scarcer in the prior era.

A fact is established that planning is a conscious and continuous process of exploring, analyzing, projecting, making concepts of and predicting the factors of the (internal, external and related) labor and organizational environment even on this basis of making planning decisions on a vision, a mission, goals, means, a strategy, plans and important planned tasks.

The effects of the flow of prediction reflect in planning assumptions (starting points, premises) that are entered into a planning documentation. Prediction may also be an autonomous activity in relation to planning. Planning and prediction are, however, interconnected, inter-causal, interdependent and inter-conditioned activities (no planning is possible without predictability). Predictability is faced with a pronounced problem, particularly so with a longer and long-time horizon, since a longer time horizon reduces the possibilities of more precise, more detailed and more successful prediction (and vice versa). Misses in prediction are frequent. Planning is potentiated as a continuous, dynamic and creative process instead of a plan as an expression, i.e. a formal or (relatively) "static" document. (5; 99-100)

\section{PLANNING MANAGEMENT DOMAINS AND SYSTEMS}

Historically observing, diverse management systems have been developing (evolving) in alignment with the growth of the challenges created by the intensification of the "turbulence", the unpredictability of the future and the complexity of the environment of a business entity (enterprise), or an organization and institution in a broader sense. The future is more complex, more intricate and less predictable, and in accordance with this, systems are becoming better-built, more sophisticated ("more refined"), more complete and wider in comparison with previous systems. Problems are more difficult or more complex at a higher level of development.

There are indicative phases and (or) stages, as well as iterations ("steps") in the development of planning and strategic management domains, i.e. areas, fields and systems.

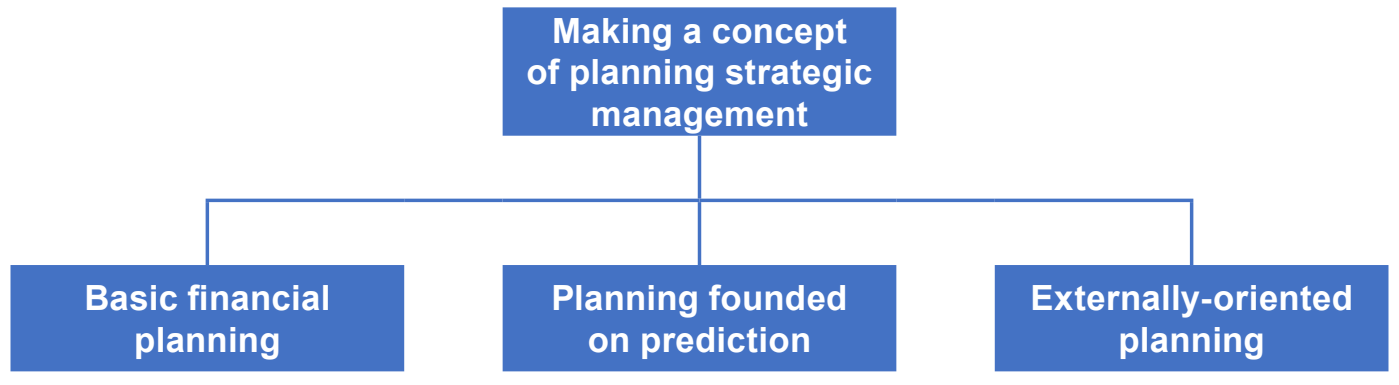

Diagram 1. The forms, phases or stages in the development of planning, strategic systems 
a) Basic financial planning is manifested as the starting (initial) phase in the creation and development (evolution) of a strategic management system. This system is possible to apply in the conditions and circumstances when the flows (of regularities) from the past are continued in the future ("extrapolation"). Changes are gradual, easy (slower). The environment of the business entity (enterprise) is known, stable and balanced. Current manufacturing-service and financial plans of a shorter term are determined based on the analysis of the past condition. The mistakes, omissions and misses of the prior planning period are also corrected. Operational (current) control and the (annual) budget are potentiated with an emphasis on manufacturing-service and financial indicators (parameters) and information in the current planning interval. The aim of this form of planning is to generate a revenue, a realization, income, a profit (the "budget", funds). In this domain, we especially speak about operational, current "budgeting".

b) Planning based on prediction is a significant expansion and "steps forward" (in comparison with prior short-term financial planning). The stress is on the analysis of the environment with the ("static") allocation of resources and means to selected business fields ("business"). The application of the system is possible when the circumstances of the environment are the marks of the predictability of a nearer future by passing on trends and tendencies from the past (the method of the "extrapolation" of data time series, mainly of a linear trend). Changes are anticipated. Long-term planning based on the extrapolation of trends from the past into the future has in the present time importantly lost its (usable, practical) value and is no longer applied in business practice.

c) Externally-oriented planning is connected with making a marketing concept and philosophy, as well as the necessity for a broader and more intensive reaction to supply, demand, prices and competition. A meticulous assessment and evaluation of determining variants and (or) alternatives is based on a breakdown analysis of the condition and situation, as well as the movement of the competition. Resources, sources and funds are (dynamically) allocated to the main directions of growth and development that more optimally enable the achievement of the goals and (or) interests of a business entity (enterprise, corporation) and another organization.

d) The projection and concept of planning strategic management enables the formation of a thought-out, more stable, fast (to a rational extent), adaptable, flexible, creative, constant and "iterative" management flow process. Planning dimensions are strategically selected. An appropriate value system and culture (a business "climate") are supported. It is indicative as the basis, research and analysis. It is aimed at having a business (or public, or social) entity react to challenges and requirements of the environment for achieving efficiency, effectiveness, successfulness (by suppressing or preventing unpredictable risks and surprises). The synchronization of all available resources of a business and organizational entity for the purpose of creating and developing mid-term and (or) long-term strategic advantages is potentiated (logically, covering also the related other tactical, short-term and operational planning or control. $(5 ; 100-103)$

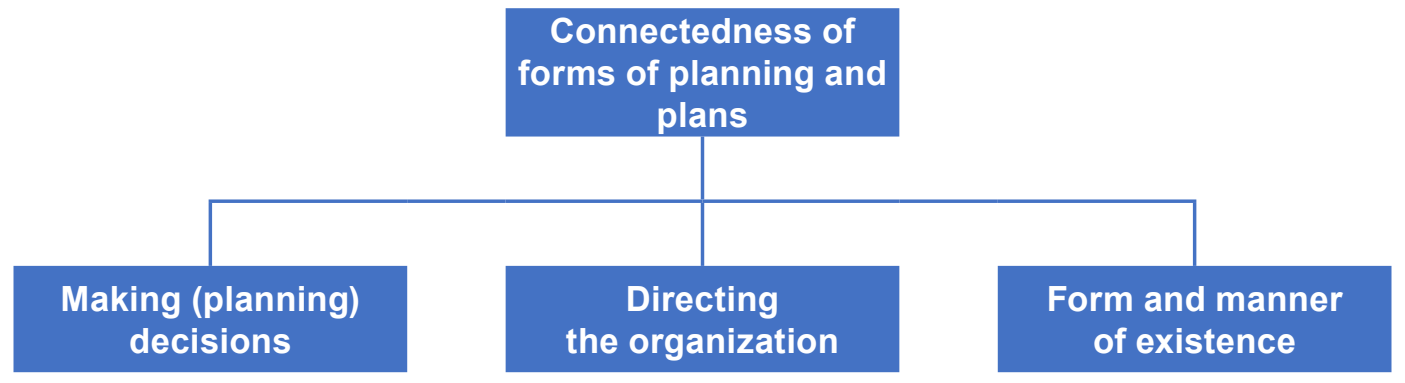

Diagram 2. The aspects, the constitutional factors of strategic planning and programming 
Nowadays, a substantial number of business entities worldwide are characterized by the insufficient growth and stagnation of or a decline in the business activity in connection with the economic-financial crisis (manifested in 2008), which (although referred to as "global"), is primarily the determinant of the western hemisphere. Through the inter-connectedness of economic, business flows, crisis effects flow over to other economic spaces. This is the era of abrupt changes, transformations, transfigurations and "discontinuities" in which (especially) the past experience is not a sufficient or fully reliable idea and the "leading idea" and underpinning for a nearer future, particularly not so for a more distant future. Sudden hits and "shocks" require adaptability as well.

Observing the evolution (i.e. the gradual flow) of its development, strategic planning of development is dynamic, multifactorial, complex and intricate, and requires more time than simple long-term planning. Strategic planning is becoming a necessity at a high level of unrest, "turbulence", when changes, modifications and challenges in the future are made or appear, respectively, in "discontinuity" (not in continuity), where these discontinuities are (at least partly) predictable. As the initial step (the "iteration"), the strong or weak sides of a business entity, as well as the other domains of a transitional form, are analyzed as the initial step (the "iteration"). It is necessary that strategic research and analysis should be performed and a choice made, and that an important strategic change should be made. $(5 ; 105)$

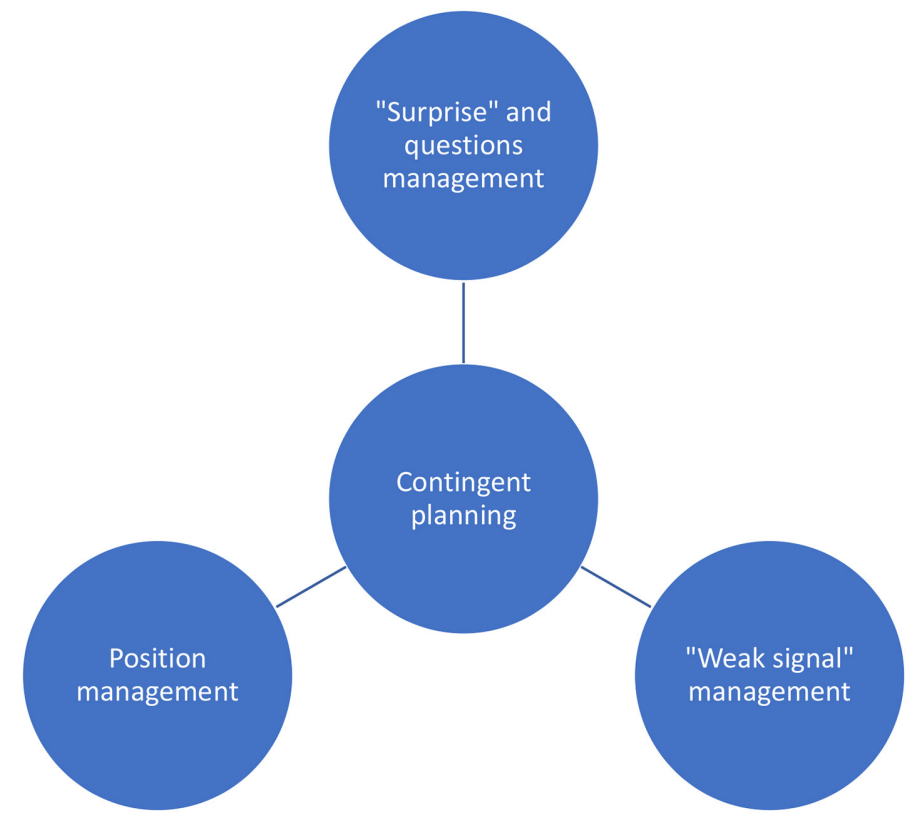

Diagram 3. The projections or concepts of planning strategic management

The strategic position of an organization, business entity (enterprise, company) means the position of the business doer on a market and changes (transformations) in comparison with the existing competition (implying disloyal competition, too). Apart from this, the strategic position should necessarily correspond with the levels of unrests, turmoil and "turbulence". There are complementary (supplementing) abilities and "levers" of an organization: a) functional (manufacturing, services, accounting, finance, personnel, marketing, etc.); b) general (management structures, decision-making by management); and c) separate, specific and special abilities (of entrepreneurship). (5; 105-107; 1; 368-369)

Contingent (multivariant) planning emphasizes the fact that different methods must necessarily be used to react to different conditions and situations in a proper and appropriate manner, not 
unilaterally in a unified manner. This system applies the "scenario method" (the creation of plans for diverse "scenarios"). More concretely, the "scenario method" signifies a tendency to shed light on and (or) identify possible flows and events in the future which are based on various premises of the trends of and changes in important factors of the environment of the organization in a future time. It is important to assess and evaluate the possibility and probability of a certain trend, flow, event, and/or phenomenon. $(5 ; 107)$

Managing strategic questions implies systematic procedures, methods and techniques of early (initial) identification and a quick and timely reaction to sudden changes and hits (or "shocks") inside and outside the business entity, i.e. in a closer and (or) more distant environment. A strategic question is a condition, dilemma, problem (internal and (or) external), with big effects on the present activity of business (and other, as well) doers, and of future effects. This planning conception is considerably simpler (than the previously mentioned). The starting premise is that a certain (small, or smaller) volume of causes is effectuated in a considerably greater scope (volume) of all results and events. It is not, however, possible to absolutely precisely determine the proportions between the volume of such causes and the volume of consequences caused. There are also urgent and (or) less urgent questions. The volume of the questions is smaller when strategic marks are concerned (and they may require a more urgent action). Certain questions require constant "monitoring" and supervision. $(5 ; 108-109)$ The planning management concept with the help of "weak signals" is also indicative.

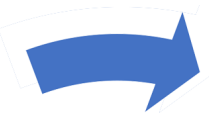

More moderate and middle signals

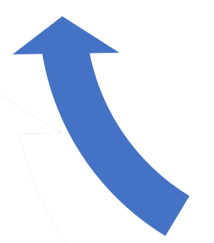

Stronger and strong signals

\section{Weak and weaker signals}

Diagram 4. The modalities of "signals" in planning, management, coordination and directing

The questions that become crystal clear by perceiving ("supervising") the environment of the organization differ from one another in the scope and (or) the structure of the included data and information. Certain questions are (immediately) determined as visible and concrete, and they belong to "stronger and strong signals". These signals enable business entities the space and chances to create special and (or) specific plans as a reaction and an activity (action) to received signals. Furthermore, other questions include insufficient and partly true, or also untrue, information in connection with the events of a future significance for the organization's business doing and development. these questions include "weak and weaker signals". Over time, such weaker signals develop ("mature") and transform into more moderate, or stronger and strong signals. When the economy and (or) a social organization expects weaker signals to become strong, then a risk of not reacting purposefully and rationally and a risk of losing the acquired strategic position appears. The necessity for an organization to start finding out the paths and 
solutions as early as in the period in which the signals of the environment are weak or weaker is manifested by the circumstances of the higher and high levels (degrees) of unrest and deformations. There are also different levels and intensities in the development of data, information and facts, as well the strength of signals (moving from lower levels to the top, or vice versa). Reacting to the signals of a divergent strength is mainly gradual, though it may also be both abrupt and in leaps and bounds. The fields (zones) of a realistic and "feasible" solution, as well as creative and action plans for the formation of "distinctive" advantages, are indicative. $(5 ; 110)$

Strategic surprise management is a more perfect management and entrepreneurial system. The future brings with itself unknowns and uncertainty ("non-transparency"). Very clearly and logically, surprises are not expected and predictable, because, if they were expected and predictable, they do not represent real surprises, either. Apart from this, we tend to manage surprises once they have happened, but this is extremely difficult to do. Understandably, conditions and situations without smaller and (or) bigger surprises are safer and more optimal. Starting from research in and analysis of military surprises (in armed forces), economic, state-owned and social organizations started (in the past) using this management system. We speak about a high level of unrest, oscillations, perturbing flows in the environment. Changed and new problems in which a subject possesses insufficient experience, or no prior experience at all, impose themselves. Answers, solutions and ways out (passages) are urgent and quick, whereas ordinary everyday systems, techniques, rules, procedures and methods are incapable of creating preconditions and conditions for an adequate and timely reaction. Unless there is an adequate answer, consequences are complex and multifold (financial collapses and turns, the melting of monetary and financial reserves, a loss of the main chances of development, appropriate variants or determining alternatives, opportunity, tangible costs and intangible expenses, and so forth). $(5 ; 111)$

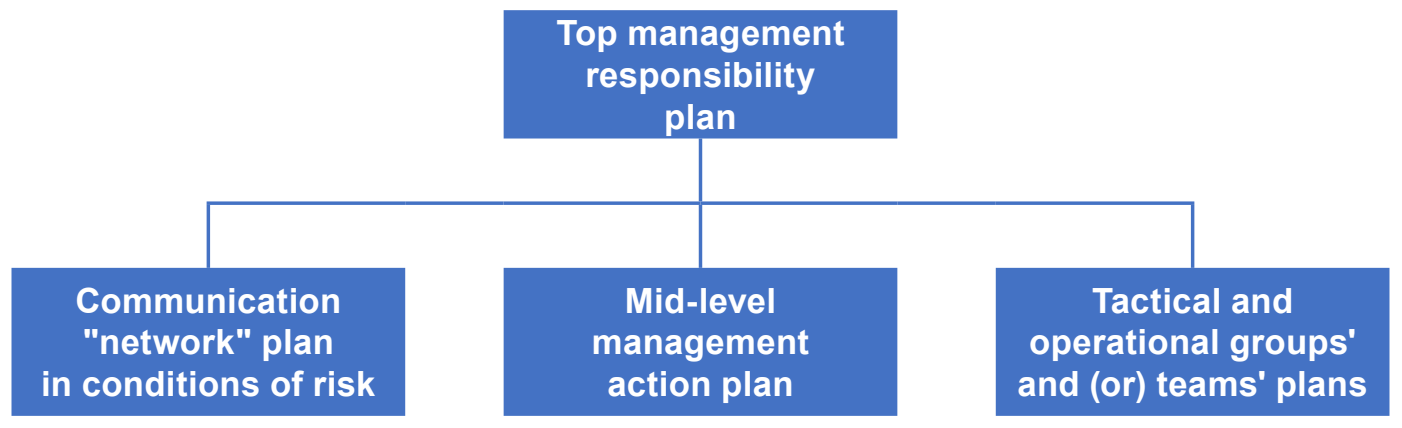

Diagram 5. The main factors of the strategic surprise management and planning system

The management decision-making structure has a responsibility of various forms (as per groups and teams), namely: answers, solutions and reactions to strong hits, "shocks" and surprises; enabling the continuity of business doing ("business") by suppressing business "friction"; the maintenance and control of ethical norms (morale) in the organization and the system; the correction of mistakes, misses and omissions, and so on. The highest level ("top" management) creates a comprehensive business projection, concept and strategy; determines the responsibility for application; directs or coordinates the flows of such realization in a goal-oriented, conscious and rational manner.

The communication "network" in conditions and cases of dangerous risks is manifested separately and exceeds the usual (normal) delimiters of the organization and achieves a more dynamic communication inside the organization as a whole. Within the "network", there is a center for the evaluation and distribution of data and information which rates and assesses 
input information and forwards them to the responsible segments of the "network" in order to find a solution. When surprises are concerned, the tactical and operational network acts in the sense that the members of a tactical and operational group and (or) team exceed the established organizational channels and lines, and form "action units" (a plan and other). A connection (communication) between management structures is directly established. These groups achieve (implement) business factors. Different networks are possible: 1. technology, 2. finance, 3. the market, 4. information and so on.

With "communication networks", tactical-operational groups (or (and) "groups") enable a faster and fast reaction and finding solutions (ways out) to changed or new problems from the aspects of creativity, research, analysis, techniques, group and (or) team work.

"Networks" are (also) indicative (as exercises) in the conditions of the nonexistence of the most critical situations.

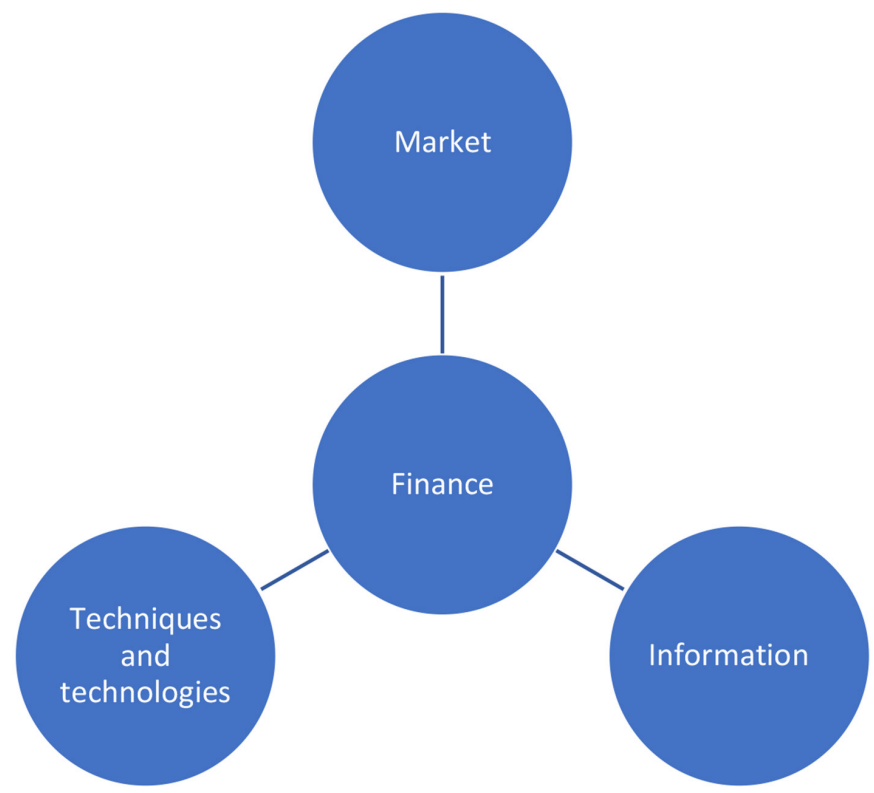

Diagram 6. Preformed and possible "networks" for different modalities of surprises

The choice of an optimal planning management for organizations and technical-economic system is of a rational character. Diversified entities and organizations should necessarily apply combined strategic management systems, as well as tactical and current operational activities (while, at the same time, it is necessary that these terms should not be confused). Furthermore, the concept of "limited rationality" is relevant. Individuals and organized systems are being faced with the difficulties and problems of a higher and high level of complexity and intricacy. Ideas about narrowing ("reducing") such intricacy emerge. Intricacy, however, is an inevitability in the contemporary conditions of business doing at all levels. Besides, the concept of "the balanced scorecard", which is considered as an acceptable planning management system, has recently been established. $(5 ; 112)$ This, however, has not exhausted the "panoply" (room, "spectrum, diapason") of possible planning management systems in the contemporary development conditions, which may still be further improved and expanded. In a more recent time (since the beginning of this century), planning has increasingly and continuously been assuming a bigger role and gaining in greater significance (at micro-, mezzo- and macro- management, organizational and technical-economic, system and other levels). The market is an economic space which is also planned in a modern manner. 


\section{CERTAIN MACRO-LEVEL PLANNING MODALITIES}

As has already been emphasized, planning is characteristic of all management and organizational levels in the economy, state and (or) society. The achieved and possible planned movements in the important macroeconomic categories are shown in the following tables:

Table 1. The real dynamics of the growth of the gross national (domestic) products in Serbia $(6 ; 12-13)$

\begin{tabular}{|c|c|c|c|c|c|c|}
\hline No. & Elements & 2006 & 2010 & 2014 & 2018 & Plan 2020 \\
\hline 1. & Real Growth (\%) & 5.1 & 0.7 & -1.6 & 1.3 & 2.9 \\
\hline
\end{tabular}

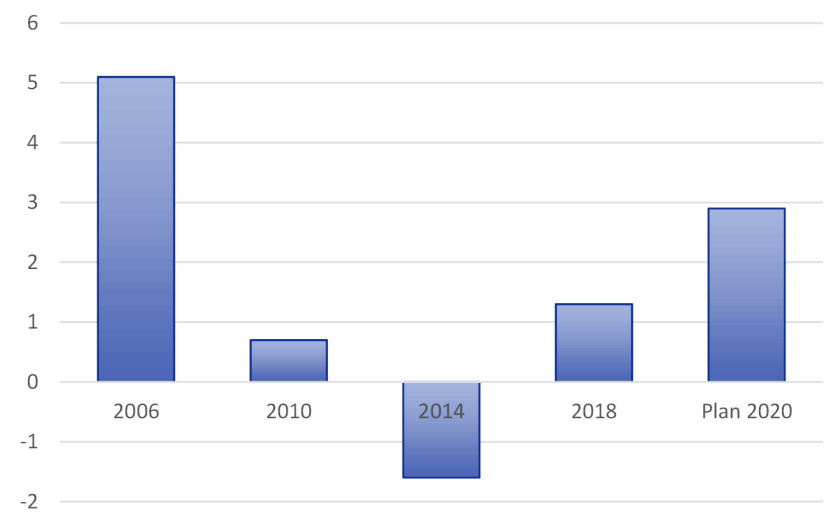

Graph 1. The real achieved and planned dynamics of the growth of the GDP presented graphically:

According to the graph, it is possible to perceive a changeable real growth of the gross national (domestic) product in Serbia in a long-term period. The planning variant of the future tendency of the growth rate is also shown.

Table 2. The trend of the structural share of domestic and foreign investments in Serbia $(6 ; 12-13)$

\begin{tabular}{|c|c|c|c|c|c|c|}
\hline No. & Elements & 2006 & 2010 & 2014 & 2018 & Plan 2020 \\
\hline 1. & Domestic investments(\%) & 21.2 & 17.7 & 15.9 & 18.7 & 21.3 \\
\hline 2. & FDIs (\%) & 12.8 & 3.6 & 3.5 & 7.5 & 7.9 \\
\hline
\end{tabular}

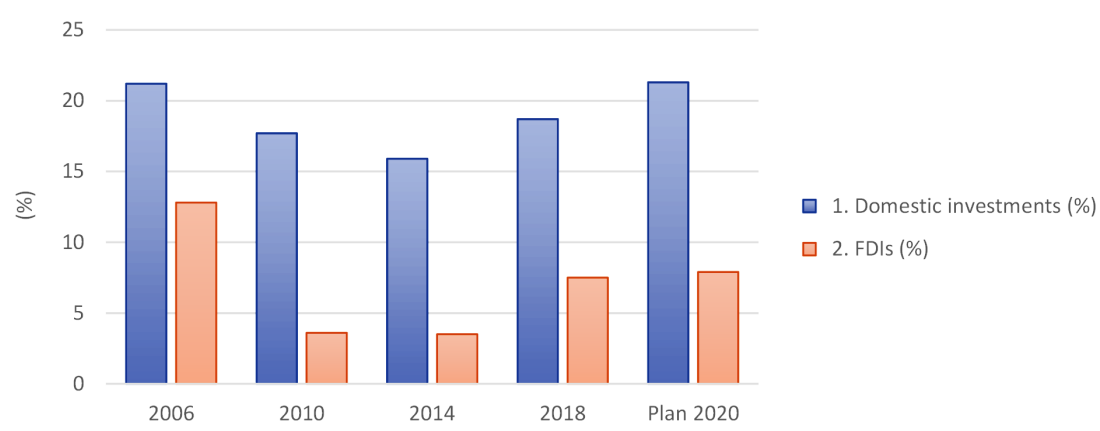

Graph 2. The structural share of investments presented graphically as well:

According to the graph, it is possible to perceive a variable tendency of the movement of the total (gross) investments into fixed (basic) funds in Serbia, reflecting on the efficiency and effectiveness of such investments $(4 ; 364-372)$. Both the achieved and the planning trends of the flows of foreign direct net investments also fluctuate. 


\section{CONCLUSION}

In this paper, possible developed variants and (or) alternatives of the planning strategic management system are presented. Strategic activities of a longer and long period are connected with tactical and (or) operational planning activities of a short and shorter term. (2;169-194, $3 ; 181-219)$ There is room for the future improvement and development of new planning systems, given the fact that there are no solutions for all time in this field, either. The absence of planning activities causes disturbances, a lack of organization and chaos in management, simultaneously with the increasing uncertainty and entropy of the overall business and other systems. The interpretations that more favorable effects are achieved through spontaneous activities without any planning (at all) are of a lay nature. These may only be coincidences. Planning is primarily monitored at the micro- (business entities), as well as mezzo- (integrations, activity branches) and macro- (social) levels. (7;195-211) More recently (at the beginning of this century, especially so after the breakout of the economic crisis of 2008) the plan has gained in significance. The market has also become the subject matter of planning.

\section{REFERENCES}

1. Dragutinović D., Filipović M., Cvetanović S. (2005), Teorija privrednog rasta i razvoja, Centar za izdavačku djelatnost Ekonomskog fakulteta u Beogradu, Beograd;

2. Đurić Z. (2011), Menadžment porodičnog biznisa, Beogradska poslovna škola, Visoka škola strukovnih studija;

3. Jančetović M., Đurić Z. (2005), Strategijski i operativni menadžment, Beogradska poslovna škola;

4. Marić D. (2012), Odnos ekonomskih načela, efikasnosti i efektivnosti sa stanovišta strategijskog menadžmenta, Zbornik radova, Međunarodni naučni skup ES-NBE (2011), Ekonomska nauka u funkciji kreiranja novog poslovnog ambijenta, Ekonomski fakultet Priština, Kosovska Mitrovica, str. 364-372;

5. Mašić B., Dželetović M. (2015), Uvod u menadžment, Inovacioni centar Fakulteta bezbjednosti Univerziteta u Beogradu, Akademska knjiga, Novi Sad;

6. Ministarstvo finansija Republie Srbije (april 2019), Bilten javnih finansija, Beograd, str. $12-13$.

7. Rikalović G. (2002), Dugoročni ekonomski razvoj - način stvaranja bogatstva, Zbornik radova Srpske akademije nauka i umjetnosti, knjiga 12, Beograd, str. 195-211. 